\title{
Epigenetic Regulation of Androgen Receptor Gene Expression in Human Prostate Cancers
}

\author{
Tsuyoshi Nakayama, Masatoshi Watanabe, Hiroyoshi Suzuki, Minoru Toyota, \\ Nobuyuki Sekita, Yoshifumi Hirokawa, Atsushi Mizokami, Haruo Ito, Ryuichi Yatani, \\ and Taizo Shiraishi
}

\begin{abstract}
Second Department of Pathology (TN, MW, YH, RY, TS), Mie University School of Medicine, Mie, and Department of Urology (HS, NS, HI), Chiba University School of Medicine, Chiba, Japan; and The Johns Hopkins Oncology Center (MT), Baltimore, Maryland; and Department of Urology (AM), Kanazawa University School of Medicine, Kanazawa, Japan
\end{abstract}

\begin{abstract}
SUMMARY: Epigenetic mechanisms including DNA methylation and histone deacetylation are thought to play important roles in gene transcriptional inactivation. Heterogenous expression of androgen receptor (AR), which appears to be related to variable responses to endocrine therapy in prostate cancer $(\mathrm{PCa})$ may also be due to epigenetic factors. The methylation status of the $5^{\prime}$ $\mathrm{CpG}$ island of the AR in 3 prostate cancer cell lines and 10 primary and 14 hormone-refractory PCa samples was determined using the bisulfite PCR methods. In DU145, CpG-rich regions of the AR were hypermethylated. By an immunohistochemical analysis, only one PCa sample had no AR expression, the others being heterogenous. Bisulfite sequencing and methylationspecific PCR analysis showed aberrant methylation of AR $5^{\prime}$-regulatory region in $20 \%$ of 10 primary and $28 \%$ of 14 hormone-refractory PCa samples. To clarify the effect of epigenetic regulation on AR expression, we treated three prostate cancer cell lines with a demethylating agent, 5-aza-2'-deoxycytidine (azaC), and a histone deacetylase inhibitor, Trichostatin A (TSA). In DU145, re-expression of AR mRNA was detected after treatment with azaC and/or TSA. Our results suggest that epigenetic regulations including $\mathrm{CpG}$ methylation and histone acetylation may play important roles in the regulation of the AR. (Lab Invest 2000, 80:1789-1796).
\end{abstract}

$P$ rostate cancers are initially androgen dependent, but most cases eventually relapse to an androgen-independent state after androgen deprivation therapy (Schroder, 1993). A key component of the androgen transduction cascade in responsive tissues is the androgen receptor (AR), and alterations in its structure and expression are thought to be responsible for the progression to androgen independence in some prostate cancers (PCa) (Culig et al, 1993). Several groups have reported involvement of AR gene mutations in primary and hormonally treated cancers, but the frequency is low (Evans et al, 1996; Suzuki et al, 1993; Taplin et al, 1995; Watanabe et al, 1997).

In immunohistochemical studies, most prostate cancers express AR to some extent, with the level of heterogeneity increasing in line with their progression to invasive prostate cancer (Magi-Galluzzi et al, 1997; Pertschuk et al, 1995). This phenomenon cannot be fully explained by AR mutations.

Recently, transcriptional silencing of genes without genetic alterations has been found to be caused by DNA methylation and histone acetylation/deacetylation, so called epigenetic mechanisms. Methylation

\section{Received June 2, 2000.}

Address reprint requests to: Dr. Masatoshi Watanabe, Second Department of Pathology, Mie University School of Medicine, 2-174 Edobashi, Tsu-shi, Mie 514, Japan. Fax: 8159231 5310; E-mail: mawata@ doc.medic.mie-u.ac.jp might directly inhibit the binding of transcription factors or methyl-cytosine binding proteins (MeCP1 and 2), which interact with other structural compounds of the chromatin, making the DNA inaccessible to transcription factors through histone deacetylation and chromatin structure change (Bird and Wolffe, 1999). Several studies have shown that DNA hypermethylation plays an important role in the inactivation of PCa-related genes such as E-cadherin, p16, and pi-class glutathione S-transferase (Graff et al, 1995; Jarrard et al, 1997; Millar et al, 1999). Recently, Jarrard et al (1998) reported their detection of aberrant methylation of the AR promoter region in several ARnegative PCa cell lines.

To clarify the involvement of epigenetic regulation in $A R$ expression, we analyzed the methylation status of the $A R 5^{\prime}$ regulatory region using the bisulfite PCR method in $3 \mathrm{PCa}$ cell lines: 10 surgically resected primary PCas and 14 hormone-refractory samples at autopsy. Additionally, we analyzed AR expression in 3 $\mathrm{PCa}$ cell lines after treatment with a demethylating agent, 5-aza-2'-deoxycytidine (azaC) and/or the histone deacetylase inhibitor, Trichostatin A (TSA).

\section{Results}

Methylation Status of AR 5' CpG Island in PCa Cell Lines

5' cytidine-guanosine (CpG) islands (Gardiner-Garden and Frommer, 1987) within the AR 5'-regulatory region 
(NCBI accession numbers X78592 and M27423) were searched, and three regions were analyzed by bisulfite PCR. As shown in Figure 1, Region 1 was located upstream, approximately 500bp from the transcription start site, and included $3 \mathrm{CpGs}$ and a cyclic-AMP response element binding protein (CREB) binding site (TGACGGAA; -506/-498: X78592) (Mizokami et al, 1994; Stubbs et al, 1996). Region 2 was around the transcription start site and included $27 \mathrm{CpG}$ dinucleotides and a single Sp1 binding site (GGGGCGGG; -46/-39: X78592) (Faber et al, 1993). Region 3 was located at the $5^{\prime}$-end of exon 1 and included 13 CpGs and polymorphic CAG repeats. Using bisulfite genomic sequencing, data was obtained for the methylation status of PCa cell lines and is summarized in Figure 2A. In the DU145 cell line, methylated cytosines in the AR promoter region (Regions 1 and 2) were seen in $30 \mathrm{CpG}$ loci (100\%). Nine of the CpG dinucleotides were completely methylated and 26 of $\mathrm{CpGs}$ were more than $60 \%$ methylated. In the PC3 and LNCaP cell lines, $10(30 \%)$ and 4 (15\%) of CpGs were methylated, and the methylation rate of each $\mathrm{CpG}$ was less than $20 \%$, except for the case of Region 1 in PC3. In Figure $2 \mathrm{~B}$, direct $\mathrm{PCR}$ sequencing data of Region 1 showed that three CpGs were methylated in DU145, but not in normal prostate samples. Representative MSP findings for Regions 2 and 3 are shown in Figure 2C. In the DU145 cell line, Regions 2 and 3 were hypermethylated, whereas they were completely unmethylated in the LNCaP and PC3 cases. In PCa cells, the methylation status detected by methylationspecific PCR (MSP) analysis was concordant with that from bisulfite genomic sequencing. In female breast tissue samples, mosaic methylation (one methylated and another unmethylated allele) could be detected using this method. These regions in normal prostate tissues were completely unmethylated. To obtain a quantitative measurement of PCR bias, we performed mixing experiments of methylated and unmethylated DNA as previously described (Warnecke et al, 1997) and showed that methylated and unmethylated alleles were amplified with almost equal efficiency (data not shown).

\section{Methylation Status of AR 5' CpG Island in Clinical Prostate Cancers}

MSP analysis showed that single AR-negative and AR-heterogenous expression tumors in 10 primary tumors had aberrant methylation in Regions 2 and 3 of the AR. In 14 hormone-refractory tumors, aberrant methylation was detected in four (28\%) (Fig. 3A). To determine the specificity of MSP primers, methylationpositive and -negative products were subcloned and sequenced. In the methylation-positive products, several CpGs were methylated, but not in the negative products (data not shown). Additionally, using the direct PCR sequencing technique, methylation of 3 CpG sites in Region 1 was determined in four primary PCas and four hormone-refractory tumors (Fig. 3B). To determine methylation of the AR gene promoter in more detail, bisulfite PCR products of one methylation-positive sample (P2) were subcloned and sequenced (Fig. 3C). Although aberrant methylation was shown by MSP analysis, several alleles were methylated in the AR promoter regions, especially in -525 to -502 (Region 1) and -56 to +50 (Region 2). Three CpGs in Region 1 were methylated approximately at $50 \%$, whereas methylated cytosines were less than $30 \%$ in Region 2. The methylation status of 10 primary and 14 hormone-refractory tumors is summarized in Table 1. Two of the primary PCa samples and four of the hormone-refractory samples were methylated in Regions 1, 2, and 3. One of the primary PCa samples (P2), the methylated AR promoter, completely lost expression of AR protein, and the other showed heterogeneous expression by an immunohistochemical method (Fig. 4). We concluded that there is no correlation between methylation state and clinicopathological factors in primary and hormonerefractory $\mathrm{PCa}$.

\section{Re-Expression of the AR in Prostate Cancer Cell Lines after azaC and/or TSA Treatments}

Using reverse transcription polymerase chain reaction (RT-PCR), AR mRNA expression in three PCa cell lines could be detected (Fig. 5A). AR mRNA was highly
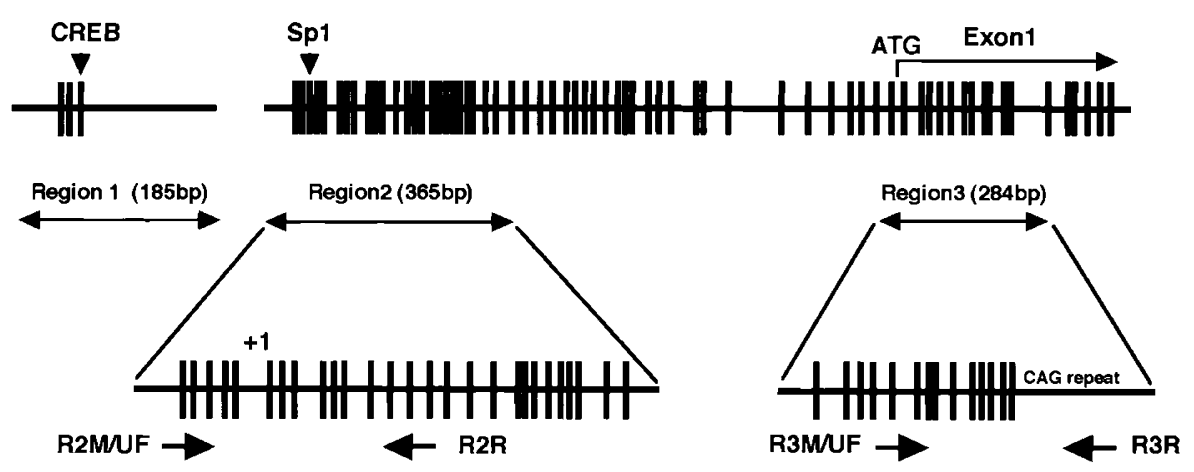

Figure 1.

Map of the androgen receptor gene $5^{\prime}$ cytidine-guanosine $(\mathrm{CpG})$ island. (Top) $\mathrm{CpG}$ density of the area is represented by vertical lines corresponding to each $\mathrm{CpG}$ site. The high density of $\mathrm{CpG}$ sites around the transcription start site (Region 2) and $5^{\prime}$ end of the first exon (Region 3 ) indicate the presence of the $\mathrm{CpG}$ island. Region 1 is located approximately 500bp upstream of the transcription start site. The position of Sp1 and cyclic-AMP response element binding protein (CREB) binding site are indicated by the arrowheads. (Bottom) Locations of the primer sets for methylation-specific PCR (MSP) is represented by bold arrow. 
A

CpG sites $\quad-525-518-502 \quad-56 \quad-51 \quad-42 \quad-35 \quad-30 \quad+4 \quad+13 \quad+21 \quad+45+50+55+81+100+109+131+139+146+160+169+179+191+193+196+202+208+211+215$

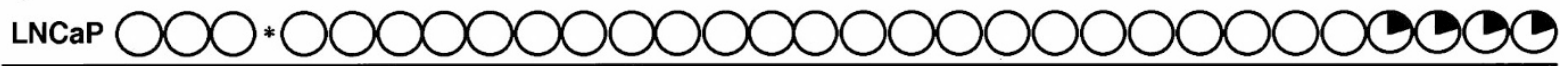

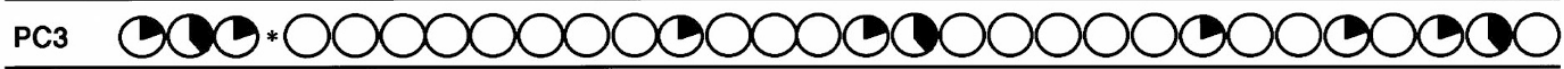

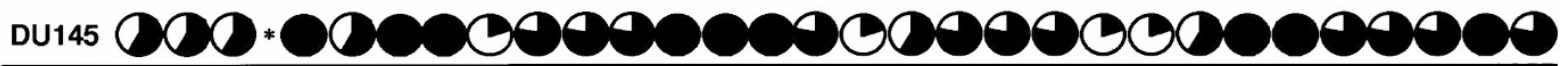
Percentage of methylation $\bigcirc 0 \% \bigcirc \sim 20 \% \bigcirc \sim 40 \% \bigcirc \sim 60 \% \bigcirc \sim 80 \% \bigcirc$

B

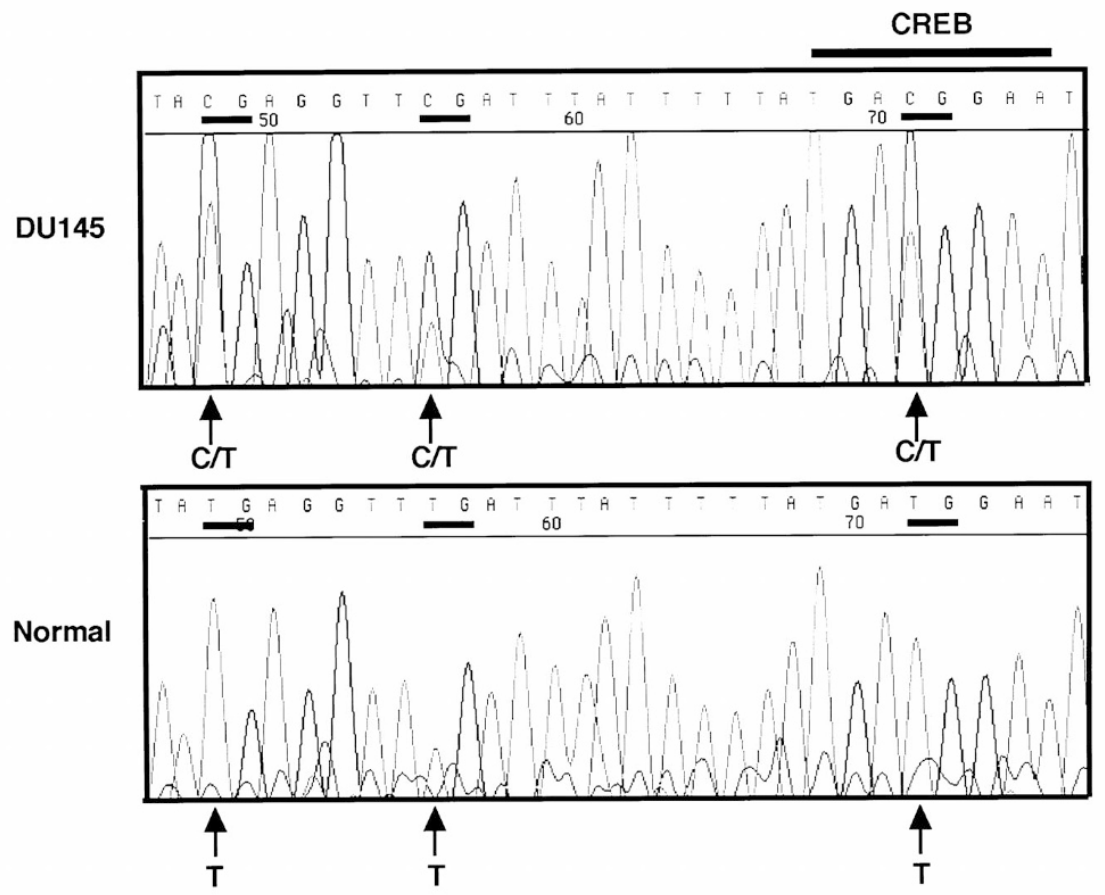

C

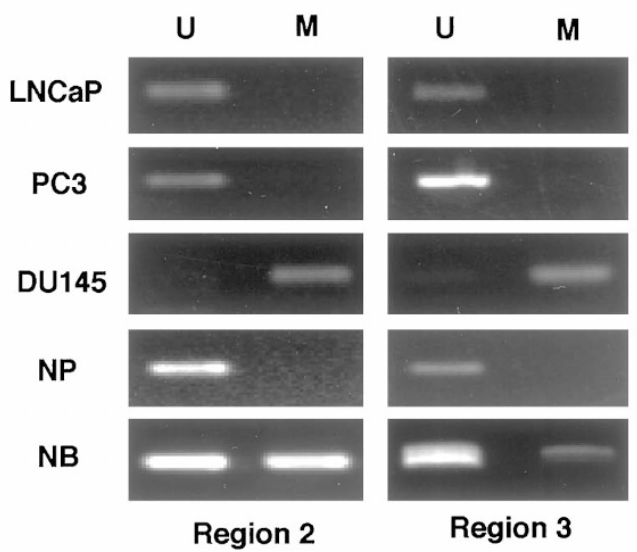

Figure 2.

A, Summarized bisulfite sequencing of androgen receptor (AR) promoter region in prostate cancer (PCa) cell lines. At least 10 clones from each cell line were analyzed to obtain percentage methylation of the $30 \mathrm{CpG}$ dinucleotides. $B$, Direct PCR sequencing of Region 1 of the AR in DU145 and a normal prostate tissue. In direct bisulfite sequencing data, CpGs were found to be partially methylated, as indicated by $\mathrm{C} / \mathrm{T}$, and unmethylated, as indicated by T. C, MSP analysis of AR promoter and exon A. NP, healthy prostate tissue; NB, healthy female breast tissue.

expressed in LNCaP cells and detected at low levels in PC3, whereas in an androgen-independent cell line, DU145, it was lacking. As shown in Figure 5B, treatment of DU145 with azaC restored AR mRNA to some extent.
Higher levels of AR re-expression were detected in DU145 cells after cotreatment with azaC and TSA (Fig. 5B). With PC3, there was no such change in AR mRNA after treatment with azaC and/or TSA (data not shown). 
A

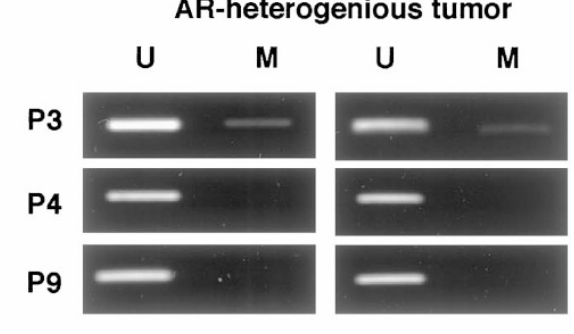

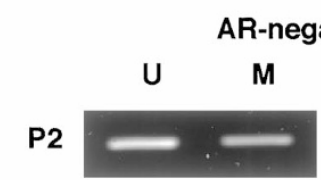

Region 2

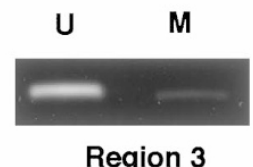

Region 3
R2

R4

R11

R12

R5

R14

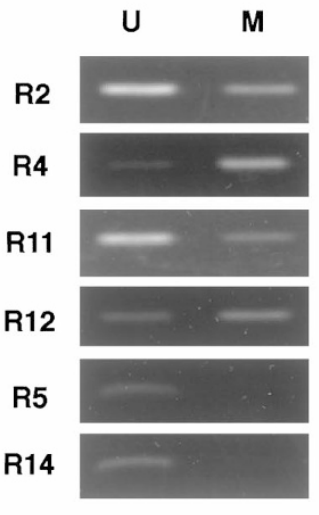

Region 2
Hormone-refractory tumor

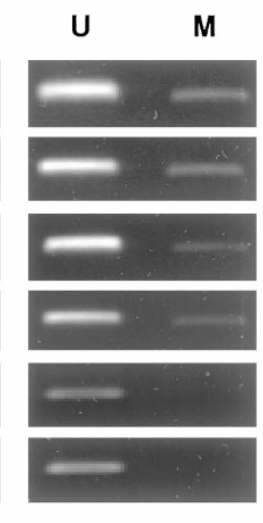

Region 3

B
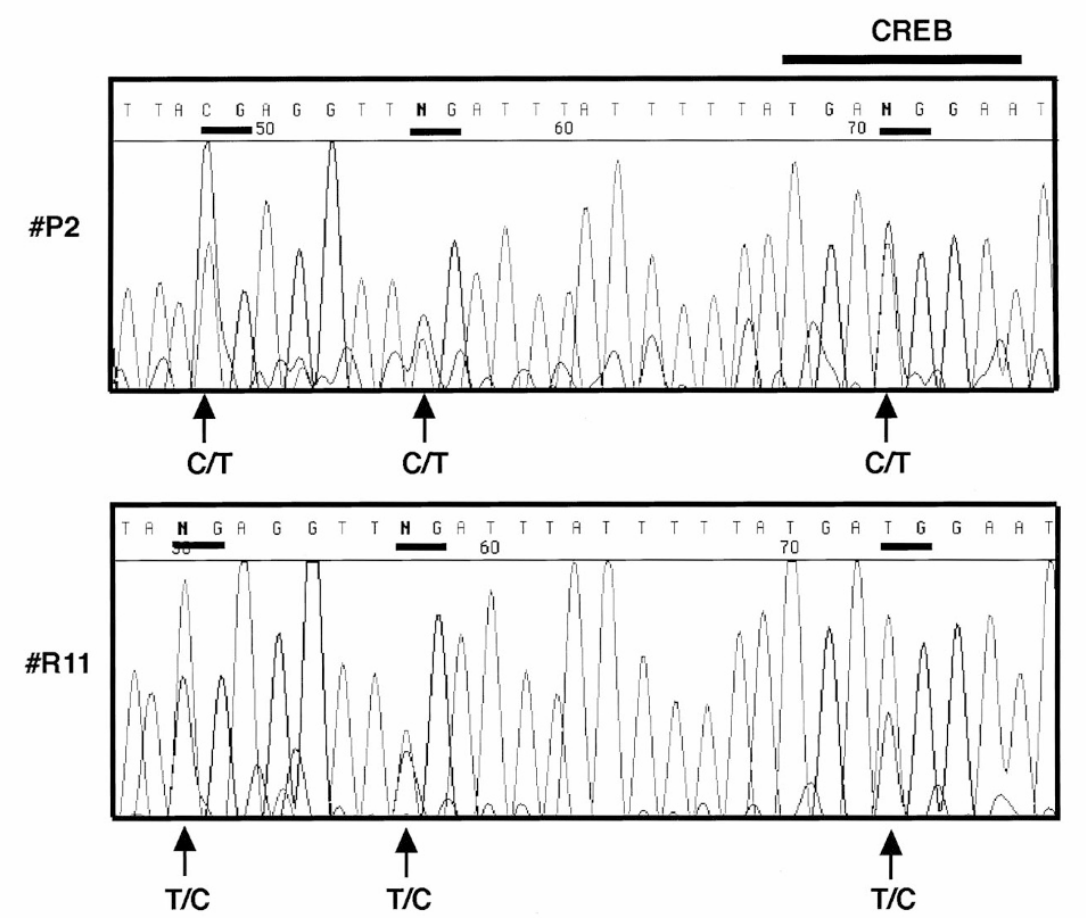

C

\#P2

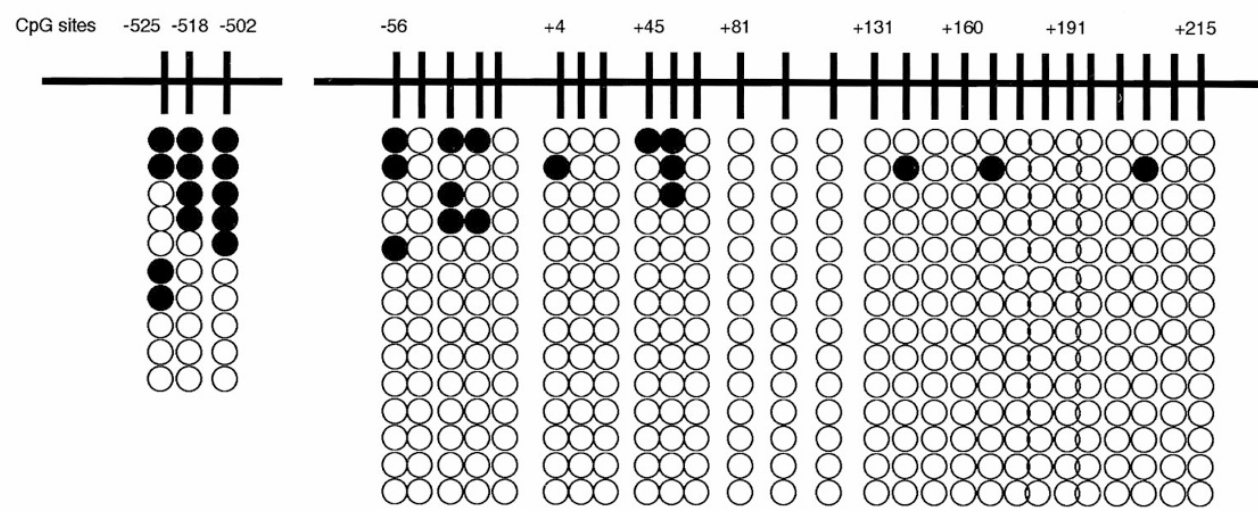

Figure 3.

A, MSP analysis of primary and refractory PCas. Aberrant methylation of Regions 2 and 3 of the AR is detected in \#P2 and \#P3. In hormone-refractory tumor samples, aberrant methylation of Regions 2 and 3 of the AR is detected in tumor samples \#R2, \#R4, \#R11, and \#R12. B, Direct PCR sequencing of Region 1 of the AR in PCas. Bisulfate sequencing of a PCa sample (\#P2) and a hormone-refractory PCa sample (\#R11) is shown. Direct-sequencing profiles reveal methylation of three CpGs in both PCa samples. C, Bisulfite sequencing of the AR promoter region. Data for sample \#P2 are represented. Methylated CpG sites are shown as filled circles and unmethylated $\mathrm{CpG}$ sites are indicated by open circles. 
Table 1. Summary of Clinicopathological Factors and Methylation in Clinical Cancers

\begin{tabular}{|c|c|c|c|c|c|c|c|}
\hline \multirow[b]{2}{*}{ Sample No. } & \multirow[b]{2}{*}{ Age } & \multirow{2}{*}{$\begin{array}{l}\text { Clinical } \\
\text { stage }\end{array}$} & \multirow{2}{*}{$\begin{array}{l}\text { Gleason } \\
\text { score }\end{array}$} & \multirow{2}{*}{$\begin{array}{c}\text { AR } \\
\text { expression }\end{array}$} & \multicolumn{3}{|c|}{ AR methylation } \\
\hline & & & & & Region 1 & Region 2 & Region 3 \\
\hline \multicolumn{8}{|c|}{ Primary prostate cancers } \\
\hline \#P1 & 61 & C & 7 & $\mathrm{H}$ & U & U & U \\
\hline \#P2 & 77 & B2 & 5 & $\mathrm{~N}$ & M & M & M \\
\hline \#P3 & 75 & C & 5 & $\mathrm{H}$ & M & M & M \\
\hline \#P4 & 60 & C & 9 & $\mathrm{H}$ & U & U & U \\
\hline \#P5 & 60 & B1 & 9 & $\mathrm{H}$ & U & U & U \\
\hline \#P6 & 66 & B1 & 7 & $\mathrm{H}$ & U & U & U \\
\hline \#P7 & 62 & B1 & 3 & $\mathrm{H}$ & U & U & U \\
\hline \#P8 & 55 & B1 & 9 & $\mathrm{H}$ & M & U & U \\
\hline \#P9 & 61 & B1 & 8 & $\mathrm{H}$ & M & U & U \\
\hline \#P10 & 64 & C & 9 & $\mathrm{H}$ & U & U & U \\
\hline \multicolumn{8}{|c|}{ Hormone-refractory tumors } \\
\hline \#R1 & 84 & D2 & 9 & ND & U & $U$ & U \\
\hline \#R2 & 66 & D2 & 8 & ND & M & M & M \\
\hline \#R3 & 65 & D2 & 8 & ND & U & U & U \\
\hline \#R4 & 68 & D2 & 7 & ND & M & M & M \\
\hline \#R5 & 79 & D2 & 9 & ND & U & U & U \\
\hline \#R6 & 78 & D2 & 9 & ND & U & U & U \\
\hline$\# \mathrm{R} 7$ & 69 & D2 & 9 & ND & U & $U$ & U \\
\hline \#R8 & 67 & D2 & 7 & ND & U & U & U \\
\hline \#R9 & 71 & D2 & 9 & ND & U & U & U \\
\hline \#R10 & 75 & D2 & 7 & ND & U & U & U \\
\hline \#R11 & 80 & D2 & 9 & ND & $M$ & $M$ & $M$ \\
\hline \#R12 & 89 & D2 & 8 & ND & $M$ & $M$ & $\mathrm{M}$ \\
\hline \#R13 & 81 & D2 & 9 & ND & U & U & U \\
\hline \#R14 & 79 & D2 & 8 & ND & U & $U$ & U \\
\hline
\end{tabular}

M, methylated; U, unmethylated; H, heterogeneous expression; N, no expression; AR, androgen receptor; ND, not determined.

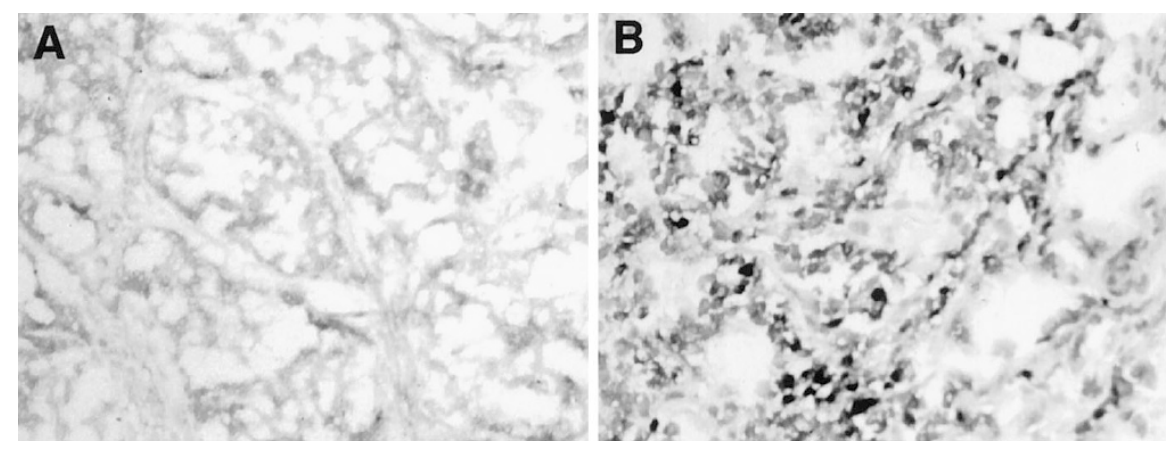

Figure 4.

Immunohistochemical staining of $\mathrm{AR}$ in primary prostate cancers. $A$, The tumor sample \# 2 has no expression of $\mathrm{AR}$. $B$, The tumor sample \#P3 has heterogeneous expression of AR.

\section{Discussion}

The $5^{\prime}$-region of genes, characterized by promoters and $\mathrm{CpG}$ islands, appears to be a target for methylation. Recently, lack of AR expression was found to correlate with aberrant methylation of AR $5^{\prime} \mathrm{CpG}$ islands in some AR-negative PCa cell lines (Jarrard et al, 1998). Methylation in Hpall and Hhal sites upstream of the CAG repeat of the AR exon1 was also reported to be correlated with the $X$ inactivation syndrome (Allen et al, 1992). In this study, we detected hypermethylation of AR 5' CpG islands in the DU145 cell line using bisulfite genomic sequencing and MSP methods, and partial demethylation-restored AR gene expression. Thus, CpG islands within the promoter region of the AR may be methylated, leading to transcriptional silencing of the AR. In the present study, methylation of clinical samples was found to be heterogenous using bisulfite PCR direct sequencing and MSP. But, in six of eight methylation-positive PCa samples, all of three AR gene 5'-regions were methylated. Bisulfite sequencing data for an AR-negative tumor (Sample P2) showed that aberrant methylation of the AR gene 
A)

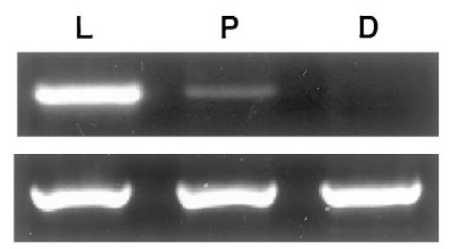

B)

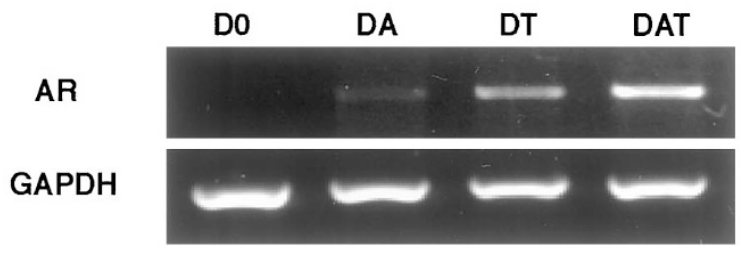

AR

\section{GAPDH}

\section{Figure 5}

$A$, AR expression of PCa cell lines. AR expression was determined by RT-PCR using primers that yield a fragment of $360 \mathrm{bp}$. $B$, The effect of the demethylating agent (azaC) and/or the deacetylation inhibitor (TSA). L, LNCaP; P, PC3; D, DU145; DO, DU145 without treatment; DA, DU145 with $2 \mu$ m azaC treatment; DT, DU145 with $100 \mathrm{ng} / \mathrm{ml}$ TSA treatment; DAT, DU145 with both azaC and TSA.

was restricted to the core promoter regions $(-525$ to -502 , and -56 to +50 ). Although most CpG sites in these regions showed a low level of methylation (10\% to $50 \%$ ), we speculated that methylation of the $A R$ gene may be heterogenous in cell populations of $\mathrm{PCa}$, as was reported previously for genetic alterations such as ras and p53 mutations (Konishi et al, 1995). Additional study using a more direct method such as in situ methylation analysis is needed to address this question.

Epigenetic mechanisms include three types of gene regulation: (a) DNA methylation, (b) histone acetylation/deacetylation; and (c) alterations in regulatory feedback loops for growth factors. Because the acetylation state of histones might be an important mechanism, we treated PCa cells with azaC and/or TSA and analyzed AR mRNA by RT-PCR. Demethylation using a methyltransferase inhibitor, azaC, was thereby found to restore AR mRNA expression. Moreover, the methylated AR gene in DU145 could be reactivated by TSA treatment alone, and much higher levels of AR mRNA were detected on cotreatment with azaC and TSA. Recent studies have proposed that methylation within the $5^{\prime}$-regulatory region may mediate gene inactivation either by causing alteration in chromatin configuration or by interfering with the binding of transcription factors. Silencing has been linked to histone deacetylation through binding of methyl-CpG binding proteins (MeCP1 and MeCP2) to methylated promoter regions (Jones et al, 1998; Ng et al, 1999; Wade et al, 1999). In the present study, the additive effects of azaC and TSA provide support for the recently described link between DNA methylation and histone deacetylation. Additionally, the effect of treatment with TSA alone suggests the interesting and unexplored possibility that TSA can affect the transcriptional regulation of genes with DNA methylation in cancer cells. DNA methylation of the $5^{\prime}$-regulatory region of the $A R$ seems to play only a partial role in silencing AR expression in DU145.

In summary, the present study revealed AR $5^{\prime} \mathrm{CpG}$ islands to be methylated heterogeneously in about $20 \%$ of clinical cancers and in the AR-negative prostate cancer cell line, DU145. In addition, it was demonstrated that epigenetic regulations such as DNA methylation and histone acetylation may play an im- portant role in controlling $A R$ expression in human prostate cancers.

\section{Materials and Methods}

\section{Cell Culture and Treatment}

Prostate cancer cell lines (LNCaP, PC3, and DU145) were obtained from the American Type Tissue Culture Collection (Manassas, Virginia). All cell lines were cultured routinely in RPMl 1640 with $10 \%$ FBS at $37^{\circ} \mathrm{C}$ with $5 \% \mathrm{CO}_{2}$. To test inactivation and re-activation, $\mathrm{PCa}$ cells were treated with 5-aza-2'-deoxycytidine (azaC; Sigma Chemical Company, St. Louis, Missouri) at a final concentration of 0.5 to $2 \mu \mathrm{M}$, or with Trichostatin A (TSA, Sigma) at a final concentration of 10 to $500 \mathrm{ng} / \mathrm{ml}$, or with both azaC and TSA for 24 to 72 hours, exchanging the medium every 24 hours.

\section{Tumor Samples}

Ten PCa samples were obtained by radical prostatectomy at Mie University Hospital, Mie, Japan, and 14 hormone-refractory tumors were obtained from distant organ-site metastases during autopsy at Chiba University Hospital, Chiba, Japan. With the latter, all 14 patients had experienced new onset of cancer under hormonal therapy and had died. All samples were diagnosed according to the Gleason scoring system and staged according to the General Rules for Clinical and Pathological Studies on Prostatic Cancer. Clinicopathological data are summarized in Table 1.

\section{DNA Extraction and Microdissection}

The surgically resected tumors were snap-frozen and microdissected to separate tumor portions. Genomic DNAs were extracted according to a standard protocol.

\section{Bisulfite PCR Methylation Analysis}

Genomic DNA $(0.5 \mu \mathrm{g})$ was treated with sodium bisulfite as described previously (Frommer et al, 1992). After denaturation in $0.3 \mathrm{M} \mathrm{NaOH}$ for 15 minutes, sodium bisulfite was added to a final concentration of 3.1 $\mathrm{M}$, and hydroquinone was added to a final con- 
centration of $0.5 \mathrm{~mm}$. The reaction was performed at $55^{\circ} \mathrm{C}$ for 16 hours, and then the solution was desalted using the Wizard DNA purification resin (Promega, Madison, Wisconsin) according to the manufacturer's directions. Bisulfite modification was completed by $0.3 \mathrm{M} \mathrm{NaOH}$ treatment at $37^{\circ} \mathrm{C}$ for 15 minutes, followed by ethanol precipitation. Methylation status of the $5^{\prime}$-regulatory region of the AR in PCa cell lines was analyzed by bisulfite PCR sequencing. Bisulfite genomic sequencing was carried out with the following primers:

Region 1 (product size 185bp): forward, 5'-GGT AGA GAA GAG GGT AGA AA-3'; reverse, 5' -CTC CTA CAA ACT AAA AAA CAA ACC-3'.

Region 2 (product size 365bp): forward, 5'-AAA AGG AGG TGG GAA GGT AA-3'; reverse, 5' -ACT TTC CTT ACT TCC TCC AA-3'.

PCR conditions were as follows: Region 1 , at $95^{\circ} \mathrm{C}$ for 10 minutes, 30 cycles of $95^{\circ} \mathrm{C}$ for 30 seconds, $58^{\circ} \mathrm{C}$ for 30 seconds, $72^{\circ} \mathrm{C}$ for 30 seconds, and $72^{\circ} \mathrm{C}$ for 10 minutes; Region 2 , at $95^{\circ} \mathrm{C}$ for 10 minutes, 30 cycles of $95^{\circ} \mathrm{C}$ for 30 seconds, $55^{\circ} \mathrm{C}$ for 30 seconds, $72^{\circ} \mathrm{C}$ for 30 seconds, and $72^{\circ} \mathrm{C}$ for 10 minutes. For bisulfite genomic sequencing, bisulfite PCR products were gel purified and directly sequenced or subcloned into the TOPO TA cloning vector (Invitrogen, San Diego, California) and sequenced using BigDye terminator method (Perkin-Elmer Cetus, Norwalk, Connecticut).

To yield a percentage methylation for each site, the numbers of methylated CpGs at specific sites were divided by the numbers of clones analyzed (at least, 10 clones for all cases). To address the problem of potential PCR bias in quantitative bisulfite methylation analysis, we performed mixing experiments as previously described (Warnecke et al, 1997). Methylated DNA controls (DU145 or Sssl methylated DNA) were diluted with unmethylated DNA controls (normal prostate or LNCaP)(0\%, 20\%, 40\%, $60 \%, 80 \%$, and 100\%). Mixed DNA samples were bisulfite treated and PCR amplified using primer sets for AR Regions 1 and 2. To determine if the methylated DNA was amplified proportionally, we chose combined bisulfite restriction analysis (Xiong and Laird, 1997). PCR products were gel-purified and digested with Taql (TCGA; -519/ -516 in Region 1) and BstU1 (CGCG; +191/+194 in Region 2). The amounts of digested products (methylated DNA products) were calculated by densitometry, and a standard curve was generated.

Methylation-specific PCR (MSP) was chosen for detection of the methylated alleles of the AR in $P C a$ samples (Herman et al, 1996) because most PCa samples were composed of heterogenous clones and contamination with normal epithelial and stromal tissues was present. In addition, MSP analysis is sensitive to $0.1 \%$ methylated alleles. Sets of primer sequences were as follows:

Region 2 (product size 183bp): for unmethylated (forward, R2U), 5'-AGG TTG GTT TGG TGG GGG T-3'; for methylated (forward, R2M), 5' -AGG TCG GTT CGG TGG GGC-3'; and (reverse, R2R) 5'-ATA GAG GGA AAA AGG GTT GAG TTA G-3'.
Region 3 (product size was varied for containing polymorphic CAG repeat): for unmethylated (forward, R3U), 5' -TAG AAT TTG TTT TAG AGT GTG TGT-3'; for methylated (forward, R3M), 5'-TTT GTT TTA GAG CGT GCG C-3'; and (reverse, R3R), 5'-AAA ACC ATC CTC ACC CTA CT-3'.

PCR was performed for 30 cycles. Annealing temperature was as follow: $58^{\circ} \mathrm{C}$ for unmethylated reaction of Region $2 ; 61^{\circ} \mathrm{C}$ for methylated reaction of Region $2 ; 60^{\circ} \mathrm{C}$ for both unmethylated and methylated reaction of Region 3. Normal prostate samples were used as negative controls, and a normal female breast sample was used as a positive control. PCR products were directly loaded onto $2.0 \%$ TBE agarose gels and visualized under UV illumination.

MSP products were obtained only from bisulfitetreated DNA and not untreated DNA. Additionally, we sequenced bisulfite PCR products directly to test whether the bisulfite reaction was complete with change of all unmethylated cytosines to uracils (sequenced as thymines). We confirmed that our data did not contain any false positive results caused by incomplete bisulfite treatment (data not shown).

\section{Analysis of AR Expression in PCa Cell Lines Treated with azaC and TSA}

Total RNA was prepared using Isogen (Nippon Gene, Tokyo, Japan) according to the manufacturer's instructions. Two $\mu \mathrm{g}$ of total RNA were used for the generation of cDNA using Superscript reverse transcriptase (GIBCO BRL, Gaithersburg, Maryland). The primers applied to detect $A R$ expression was as follows: 5'-GCA TGG CAG AGT GCC CTA TC3' (forward) and 5'-TCC CAG AGT CAT CCC TGC TTC AT-3' (reverse) (Taplin et al, 1995). PCR amplification was performed for 35 cycles of $95^{\circ} \mathrm{C}$ for 30 seconds, $60^{\circ} \mathrm{C}$ for 30 seconds, and $72^{\circ} \mathrm{C}$ for 30 seconds. Human glyceraldehyde-3-phosphate dehydrogenase (GAPDH) served as an internal control. The PCR products were electrophoresed in $2.0 \%$ TBE agarose gels and visualized by ethidium bromide staining.

\section{Immunohistochemical Analysis of AR Expression}

Frozen sections of the 10 surgically resected primary tumor samples were immunostained with anti-AR polyclonal antibody (a gift of Dr. A. Mizokami, Kanazawa University School of Medicine, Kanazawa, Japan), using an automated Ventana NX instrument (Ventana Medical Systems, Tucson, Arizona).

\section{References}

Allen RC, Zoghbi HY, Moseley AB, Rosenblatt HM, and Belmont JW (1992). Methylation of Hpall and Hhal sites near the polymorphic CAG repeat in the human androgenreceptor gene correlates with $X$ chromosome inactivation. Am J Hum Genet 51(6):1229-1239.

Bird AP and Wolffe AP (1999). Methylation-induced repression-belts, braces, and chromatin. Cell 99:451-454. 
Culig ZH, Obisch A, Hittmair A, Peterziel H, Cato AC, Bartsch $G$, and Klocker $H$ (1993). Expression, structure, and function of androgen receptor in advanced prostatic carcinoma. Prostate 35:63-70.

Evans BA, Harper ME, Daniells CE, Watts CE, Matenhelia S, Green J, and Griffiths K (1996). Low incidence of androgen receptor gene mutations in human prostatic tumors using single strand conformation polymorphism analysis. Prostate 28:162-171.

Faber PW, van Rooij HC, Schipper HJ, Brinkmann AO, and Trapman J (1993). Two different, overlapping pathways of transcription initiation are active on the TATA-less human androgen receptor promoter. The role of Sp1. J Biol Chem 268:9296-9301.

Frommer M, McDonald LE, Millar DS, Collis CM, Watt F, Grigg GW, Molloy PL, and Paul CL (1992). A genomic sequencing protocol that yields a positive display of 5-methylcytosine residues in individual DNA strands. Proc Natl Acad Sci USA 89:1827-1831.

Gardiner-Garden M and Frommer M (1987). CpG islands in vertebrate genomes. J Mol Biol 196:261-282.

Graff JR, Herman JG, Lapidus RG, Chopra H, Xu R, Jarrard DF, Isaacs WB, Pitha PM, Davidson NE, and Baylin SB (1995). E-cadherin expression is silenced by DNA hypermethylation in human breast and prostate carcinoma. Cancer Res 55:5195-5199.

Herman JG, Graff JR, Myohanen S, Nelkin BD, and Baylin SB (1996). Methylation-specific PCR: A novel PCR assay for methylation status of CpG islands. Proc Natl Acad Sci USA 93:9821-9826.

Jarrard DF, Bova GS, Ewing CM, Pin SS, Nguyen SH, Baylin SB, Cairns P, Sidransky D, Herman JG, and Isaacs WB (1997). Deletional, mutational, and methylation analyses of CDKN2 (p16/MTS1) in primary and metastatic prostate cancer. Genes Chromosomes Cancer 19:90-96.

Jarrard DF, Kinoshita H, Shi Y, Sandefur C, Hoff D, Meisner LF, Chang C, Herman JG, Isaacs WB, and Nassif N (1998). Methylation of the androgen receptor promoter $\mathrm{CpG}$ island is associated with loss of androgen receptor expression in prostate cancer cells. Cancer Res 58:5310-5314.

Jones PL, Veenstra GJ, Wade PA, Vermaak D, Kass SU, Landsberger N, Strouboulis J, and Wolffe AP (1998). Methylated DNA and MeCP2 recruit histone deacetylase to repress transcription. Nat Genet 19:187-191.

Konishi N, Hiasa Y, Matsuda H, Tao M, Tsuzuki T, Hayashi I, Kitahori Y, Shiraishi T, Yatani R, and Shimazaki J (1995). Intratumor cellular heterogeneity and alterations in ras oncogene and p53 tumor suppressor gene in human prostate carcinoma. Am J Pathol 147:1112-1122.

Magi-Galluzzi C, Xu X, Hlatky L, Hahnfeldt P, Kaplan I, Hsiao P, Chang C, and Loda M (1997). Heterogeneity of androgen receptor content in advanced prostate cancer. Mod Pathol 10:839-845.
Millar DS, Ow KK, Paul CL, Russell PJ, Molloy PL, and Clark SJ (1999). Detailed methylation analysis of the glutathione S-transferase pi(GSTP1) gene in prostate cancer. Oncogene 18:1313-1324.

Mizokami A, Yeh SY, and Chang C (1994). Identification of $3^{\prime}, 5^{\prime}$-cyclic adenosine monophosphate response element and other cis-acting elements in the human androgen receptor gene promoter. Mol Endocrinol 8:77-88.

$\mathrm{Ng} \mathrm{HH}$, Zhang $\mathrm{Y}$, Hendrich B, Johnson CA, Turner BM, Erdjument-Bromage $\mathrm{H}$, Tempst $\mathrm{P}$, Reinberg $\mathrm{D}$, and Bird $\mathrm{A}$ (1999). MBD2 is a transcriptional repressor belonging to the MeCP1 histone deacetylase complex. Nat Genet 23:58-61.

Pertschuk LP, Schaeffer H, Feldman JG, Macchia RJ, Kim YD, Eisenberg K, Braithwaite LV, Axiotis CA, Prins G, and Green GL (1995). Immunostaining for prostate cancer androgen receptor in paraffin identifies a subset of men with a poor prognosis. Lab Invest 73:302-305.

Schroder FH (1993). Endocrine therapy for prostate cancer: Recent developments and current status. Br J Urol 71:633640.

Stubbs AP, Lalani EN, Stamp GW, Hurst H, Abel P, and Waxman J (1996). Second messenger up-regulation of androgen receptor gene transcription is absent in androgen insensitive human prostatic carcinoma cell lines, PC-3 and DU-145. FEBS Lett 383:237-240.

Suzuki $H$, Sato $N$, Watabe $Y$, Masai $M$, Seino $S$, and Shimazaki J (1993). Androgen receptor gene mutations in human prostate cancer. J Steroid Biochem Mol Biol 46:759_ 765.

Taplin ME, Bubley GJ, Shuster TD, Frantz ME, Spooner AE, Ogata GK, Keer HN, and Balk SP (1995). Mutation of the androgen-receptor gene in metastatic androgenindependent prostate cancer. N Engl J Med 332:1393-1398.

Wade PA, Gegonne A, Jones PL, Ballestar E, Aubry F, and Wolffe AP (1999). Mi-2 complex couples DNA methylation to chromatin remodelling and histone. Nat Genet 23:62-66.

Watanabe M, Ushijima T, Shiraishi T, Yatani R, Shimazaki J, Kotake T, Sugimura T, and Nagao M (1997). Genetic alterations of androgen receptor gene in Japanese human prostate cancer. Jpn J Clin Oncol 27:389-393.

Warnecke PM, Stirzaker C, Melki JR, Millar DS, Paul CL, and Clark SJ (1997). Detection and measurement of PCR bias in quantitative methylation analysis of bisulphite-treated DNA. Nucleic Acids Res 25:4422-4426.

Xiong Z and Laird PW (1997). COBRA: A sensitive and quantitative DNA methylation assay. Nucleic Acids Res 25: 2532-2534. 